\title{
Blood pressure goal achievement with olmesartan medoxomil-based treatment: additional analysis of the OLMEBEST study
}

This article was published in the following Dove Press journal:

Vascular Health and Risk Management

26 August 2009

Number of times this article has been viewed

\author{
Vivencio Barrios' \\ Carlos Escobar' \\ Alberto Calderon ${ }^{2}$ \\ Michael Böhm ${ }^{3}$ \\ 'Department of Cardiology, \\ Hospital Ramón y Cajal, Madrid, \\ Spain; ${ }^{2}$ Primary Care Center Rosa \\ de Luxemburgo, Madrid, Spain; \\ ${ }^{3}$ Klinik für Innere Medizin III, \\ Universitätsklinikum des Saarlandes, \\ Homburg/Saar, Germany
}

Aims: Guidelines recommend blood pressure (BP) in hypertensive patients should be $<140$ systolic BP (SBP) and $<90$ diastolic BP (DBP) mmHg. This analysis assessed goal rate achievement in hypertensive patients receiving olmesartan-based treatment in the OLMEBEST study.

Methods: Patients with essential hypertension (DBP $\geq 90 \mathrm{mmHg}$ and $<110 \mathrm{mmHg}$ ) received open-label olmesartan medoxomil $20 \mathrm{mg}$ /day $(\mathrm{n}=2306)$. After 8 weeks, patients with DBP $\geq 90 \mathrm{mmHg}(\mathrm{n}=627)$ were randomized to 4 weeks' double-blind treatment with olmesartan $40 \mathrm{mg}$ /day monotherapy or olmesartan $20 \mathrm{mg}$ /day plus hydrochlorothiazide (HCTZ) $12.5 \mathrm{mg} /$ day. For this analysis, the numbers and proportions of patients who achieved $\mathrm{SBP}<140 \mathrm{mmHg}$ and/or DBP $<90 \mathrm{mmHg}$ at the end of the 4 weeks were calculated.

Results: In patients who achieved DBP normalization $(<90 \mathrm{mmHg})$ at week $8(\mathrm{n}=1546)$ and continued open-label olmesartan $20 \mathrm{mg}$ /day, 66.7\% achieved SBP/DBP $<140 / 90 \mathrm{mmHg}$ at Week 12. In patients who did not achieve DBP normalization at Week 8, 26.8\% of those randomized to olmesartan $40 \mathrm{mg} /$ day and $42.5 \%$ of those randomized to olmesartan $20 \mathrm{mg} /$ day plus HCTZ $12.5 \mathrm{mg} /$ day achieved a SBP/DBP $<140 / 90 \mathrm{mmHg}$ at Week 12 .

Conclusion: Olmesartan $40 \mathrm{mg}$ /day and olmesartan $20 \mathrm{mg}$ /day plus HCTZ $12.5 \mathrm{mg}$ /day allow substantial proportions of patients to achieve BP goals.

Keywords: olmesartan medoxomil, hypertension, angiotensin II receptor blocker, goal rates, hydrochlorothiazide

\section{Introduction}

Hypertension is the leading cause of cardiovascular (CV) disease worldwide, ${ }^{1}$ and often occurs in conjunction with other risk factors such as dyslipidemia, diabetes and obesity, putting patients at substantial risk of CV events such as stroke and myocardial infarction. ${ }^{2}$ Due to the link between hypertension and CV risk, current guidelines recommend that all hypertensive patients should aim to reach the goal of $<140 \mathrm{mmHg}$ systolic blood pressure (SBP) and $<90 \mathrm{mmHg}$ diastolic BP (DBP). ${ }^{3,4}$ For diabetic patients and those with an elevated $\mathrm{CV}$ risk due to associated conditions, the BP goal is $130 / 80 \mathrm{mmHg}$.

Current recommendations state that the initial therapeutic regimen used to achieve BP goal should be based on a low dose of either a single agent or dual combination therapy. ${ }^{3,4}$ However, the majority of patients with hypertension will not achieve BP goals with initial low-dose monotherapy, regardless of the antihypertensive agent that is used. ${ }^{4}$ Therefore in these patients, it is recommended to either increase the dose of single-agent therapy or initiate combination treatment. ${ }^{4}$
Correspondence: Vivencio Barrios Department of Cardiology, Hospital Ramón y Cajal, Ctra. De Colmenar km 9, 100, 28034 Madrid, Spain

Tel +34913368259

Fax +34913368665

Email vbarriosa@meditex.es or vbarrios.hrc@salud.madrid.org 
Blockade of the angiotensin II type $1\left(\mathrm{AT}_{1}\right)$ receptor is an effective way to block the renin-angiotensin system and reduce BP. ${ }^{5}$ Olmesartan medoxomil, the most recently introduced angiotensin receptor blocker (ARB), was launched in the US and Europe in 2002, and in comparative studies has been shown to provide greater BP control relative to other ARBs for the doses used. ${ }^{6-10}$ In patients who do not respond adequately to the standard $20 \mathrm{mg}$ /day dose of olmesartan, the dose can be increased to $40 \mathrm{mg}$ /day to increase efficacy without affecting tolerability. ${ }^{11,12}$

Combination therapy with olmesartan and hydrochlorothiazide (HCTZ) has been shown to provide BP-lowering efficacy that is greater than that achieved with either agent individually. ${ }^{13}$ OLMEBEST enrolled 2306 patients in a partially-randomized study in which olmesartan $40 \mathrm{mg} /$ day and the combination of olmesartan $20 \mathrm{mg}$ /day plus HCTZ $12.5 \mathrm{mg} /$ day provided additional well-tolerated BP reductions in patients who had not achieved DBP normalization ( $<90 \mathrm{mmHg}$ ) after open-label treatment with olmesartan $20 \mathrm{mg} /$ day. ${ }^{14}$ The original report described the changes in BP seen during the OLMEBEST trial, and this additional analysis describes the levels of BP goal achievement obtained during this study.

\section{Patients and methods}

The design of the OLMEBEST study has been reported previously, ${ }^{14}$ so is described only briefly here.

\section{Study design}

This was a prospective, parallel-group, double-blind, double-dummy study (Figure 1). The study population comprised males and females (aged 18 to 75 years) with essential hypertension (DBP $\geq 90 \mathrm{mmHg}$ and $<110 \mathrm{mmHg}$ ). After a placebo run in, the study comprised an 8-week open-label phase followed by a final 4-week phase in which patients continued with open-label therapy or underwent treatment intensification by random assignment to dose uptitration or combination therapy. Patients with a normalized DBP $(<90 \mathrm{mmHg})$ at the end of open-label treatment (Week 8) continued with this treatment for a further 4 weeks. Patients whose DBP was not normalized (ie, $\geq 90 \mathrm{mmHg}$ ) at Week 8 went on to receive 4 weeks of randomized therapy. Thus, the study comprised three consecutive phases:

1. 2 weeks of placebo treatment.

2. 8 weeks of open-label treatment with olmesartan $20 \mathrm{mg} /$ day.

3. 4 weeks of either:

a. randomized treatment in which patients with a DBP $\geq 90 \mathrm{mmHg}$ at Week 8 received either olmesartan $40 \mathrm{mg}$ /day or olmesartan $20 \mathrm{mg}$ /day plus HCTZ $12.5 \mathrm{mg} /$ day.

b. open-label treatment in which patients with a DBP $<90 \mathrm{mmHg}$ at Week 8 continued with olmes$\operatorname{artan} 20 \mathrm{mg} /$ day.
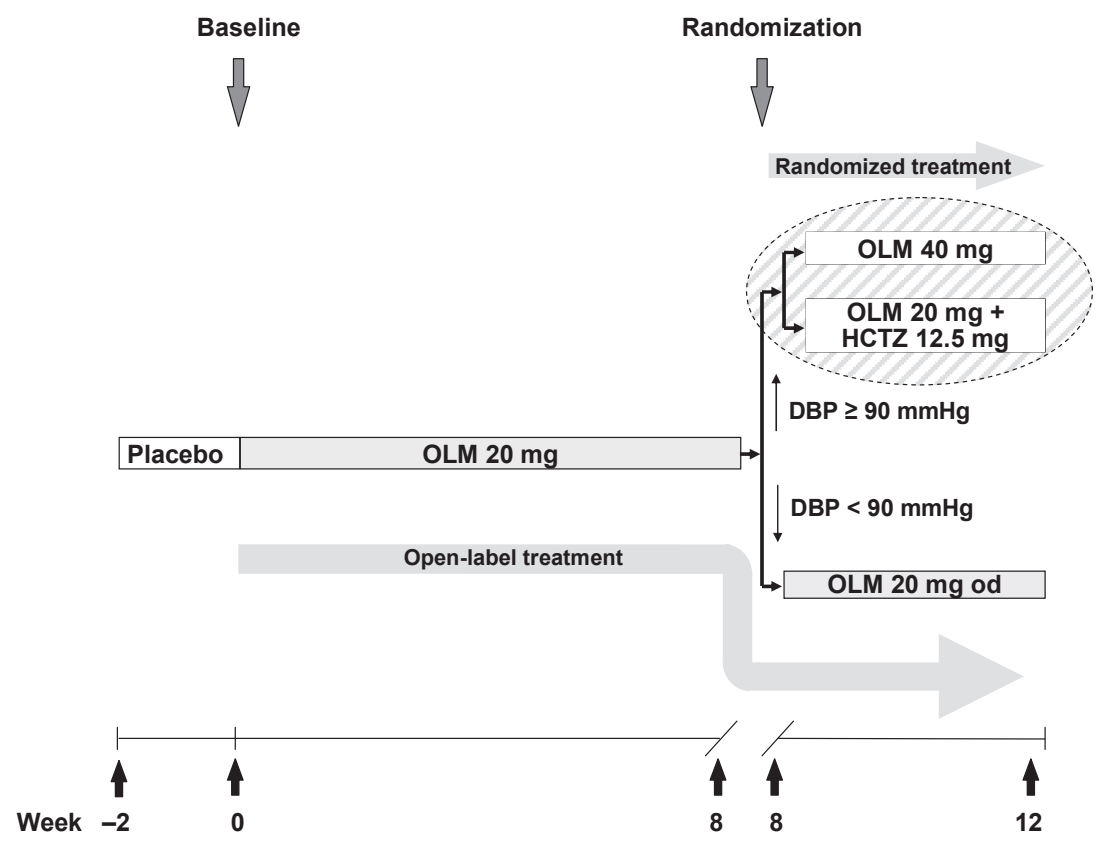

Figure I Study design.

Abbreviations: DBP, diastolic blood pressure; OLM, olmesartan; HCTZ, hydrochlorothiazide. 
Additional antihypertensive medications were not permitted during the study. The trial protocol was reviewed by an independent ethics committee or institutional review board in each country in which the trial was conducted. The trial was performed in accordance with the Declaration of Helsinki, the ethical principles of the International Conference on Harmonisation Guidelines for Good Clinical Practice, and relevant national laws of participating countries. All patients provided written informed consent.

\section{Assessments}

The assessments and timing of assessments is described in full elsewhere and is described only briefly here. ${ }^{14}$

Patients attended a study center for six assessment visits between the initiation of screening and the completion of the partially randomized period; the timing of these visits was: Weeks $-2,0,2,4,8$, and 12, respectively. Physical investigations (including vital signs and resting electrocardiogram), blood sampling for laboratory examinations, and BP recordings were performed at Visit 1 (Week -2). At all visits, seated SBP and DBP were recorded for each patient in both arms, using an appropriately sized cuff and a well-calibrated sphygmomanometer with a maximum rate of descent of $2 \mathrm{mmHg}$. Patients were questioned about possible adverse events (AEs) at Visit 2 (baseline) and all subsequent visits.

Since analysis of BP goal achievement was not included in the original study protocol, the aim of this additional analysis was to describe the level of BP control achieved at Visit 6 (Week 12) in patients who were randomized at Visit 5 (Week 8) to receive either olmesartan $40 \mathrm{mg} /$ day or olmesartan $20 \mathrm{mg}$ /day in combination with HCTZ $12.5 \mathrm{mg}$ /day, as well as in the non-randomized patients who were still in the study at Week 8 , and continued to receive olmesartan $20 \mathrm{mg}$ /day until Visit 6.

\section{Patients}

A total of 2173 patients completed the first 8 weeks of open-label treatment, of whom $71 \%(n=1546)$ continued therapy with olmesartan $20 \mathrm{mg} /$ day. A total of 627 patients did not achieve DBP normalization with olmesartan $20 \mathrm{mg} /$ day at Week 8 and were randomized to either olmesartan $40 \mathrm{mg} /$ day $(\mathrm{n}=302)$ or a combination of olmesar$\tan 20 \mathrm{mg} / \mathrm{HCTZ} 12.5 \mathrm{mg} /$ day $(\mathrm{n}=325)$. Demographic and clinical characteristics of these patients, approximately $10 \%$ of whom had diabetes mellitus, are shown in Table 1.

\section{Statistical analyses}

Data were summarized by the calculation of absolute and relative frequencies of BP goal achievement. No inferential statistics were performed during this additional analysis. Missing values at Visit 6 (Week 12) were replaced on a last observation carried forwards basis.

\section{Results \\ Goal rate achievement}

Overall, for the total population, the proportion of patients who achieved the combined BP goal of $<140 / 90 \mathrm{mmHg}$ at Week 12 was $57.6 \%(1251 / 2173)$. The proportions of the total population who achieved the individual goals

Table I Summary of demographic and clinical characteristics

\begin{tabular}{|c|c|c|c|}
\hline \multirow[t]{2}{*}{ Characteristic } & \multirow{2}{*}{$\begin{array}{l}\text { Non-randomized patients } \\
\text { Olmesartan } \\
20 \text { mg/day } \\
(n=1546)\end{array}$} & \multicolumn{2}{|c|}{ Randomized patients } \\
\hline & & $\begin{array}{l}\text { Olmesartan } \\
40 \mathrm{mg} / \mathrm{day} \\
(\mathrm{n}=302)\end{array}$ & $\begin{array}{l}\text { Olmesartan } 20 \mathrm{mg} / \mathrm{day}+ \\
\text { HCTZ I } 2.5 \mathrm{mg} / \mathrm{day} \\
(\mathrm{n}=325)\end{array}$ \\
\hline Male, \% & 50.7 & 63.2 & 57.8 \\
\hline Caucasian, \% & 98.7 & 97.4 & 98.5 \\
\hline Body mass index $\left(\mathrm{kg} / \mathrm{m}^{2}\right)$ & $28.4 \pm 4.8$ & $29.4 \pm 5.2$ & $29.6 \pm 5.2$ \\
\hline Age (years) & $55.1 \pm I I . I$ & $54.8 \pm 10.9$ & $54.9 \pm 10.1$ \\
\hline Diabetic, \% & 5.8 & 9.9 & 9.5 \\
\hline Baseline SBP (mmHg) & $154.2 \pm 13.0$ & $160.8 \pm 14.2$ & $160.8 \pm 14.0$ \\
\hline Baseline DBP (mmHg) & $96.6 \pm 4.8$ & $100.8 \pm 5.6$ & $100.2 \pm 5.1$ \\
\hline
\end{tabular}

Data for the two randomized groups are reproduced from Barrios V, Boccanelli A, Ewald S, et al. Efficacy and tolerability of olmesartan medoxomil in patients with mild to moderate essential hypertension: the OLMEBEST study. Clin Drug Investig. 2007;27:545-558 ${ }^{14}$ with permission from Wolters Kluwer Health | Adis (@ Adis Data Information BV 2007. All rights reserved).

Values are mean \pm standard deviation, except where indicated.

Abbreviations: DBP, diastolic blood pressure; HCTZ, hydrochlorothiazide; SBP, systolic blood pressure. 
of $\mathrm{SBP}<140$ and $\mathrm{DBP}<90 \mathrm{mmHg}$ were 62.7 and $79.4 \%$, respectively.

In patients who achieved DBP normalization $(<90 \mathrm{mmHg})$ at Week 8 and continued to receive open-label olmesartan $20 \mathrm{mg}$ /day until Week 12, approximately two thirds achieved the BP goal of $<140 / 90 \mathrm{mmHg}$ at Week 12 (Figure 2a). The proportions who achieved the individual goals of SBP $<140$ and DBP $<90 \mathrm{mmHg}$ were $69.3 \%$ and $90.1 \%$, respectively (Figure 2b). For patients whose DBP was $\geq 90 \mathrm{mmHg}$ at Week 8 , treatment intensification by randomization to either olmesartan $40 \mathrm{mg} /$ day or olmesartan $20 \mathrm{mg} /$ day plus HCTZ $12.5 \mathrm{mg} /$ day resulted in improved BP control. By Week 12, the overall proportion of patients in the two randomized groups with DBP $<90 \mathrm{mmHg}$ was $53.1 \%$ $(333 / 627)$, and the proportion who achieved the combined BP goal of $<140 / 90 \mathrm{mmHg}$ was $34.9 \%$ (219/627). Looking at the randomized treatment groups individually, the proportion of patients who achieved the combined BP goal of $<140 / 90 \mathrm{mmHg}$ was greater in the group that received olmesartan $20 \mathrm{mg}$ /day plus HCTZ $12.5 \mathrm{mg}$ /day (42.5\% vs $26.8 \%$; Figure 2a). Differences between these two groups in proportions who achieved the individual goal of SBP $<140$ and DBP $<90 \mathrm{mmHg}$ were somewhat less marked (Figure 2b).

For patients who received olmesartan monotherapy only (ie, non-randomized patients who received olmesartan $20 \mathrm{mg} /$ day plus the randomized patients who received olmesartan $40 \mathrm{mg} /$ day), the proportion who achieved the combined BP goal of $<140 / 90 \mathrm{mmHg}$ at Week 12 was $60.3 \%$ (1113/1848). The proportions of monotherapy recipients who achieved the individual goals of SBP $<140$ and DBP $<$ $90 \mathrm{mmHg}$ were $64.5 \%$ and $83.1 \%$, respectively.

In addition to the combined BP goal of $<140 / 90 \mathrm{mmHg}$, the proportion of patients who achieved a more rigorous combined BP goal of $<130 / 85 \mathrm{mmHg}$ was also assessed. For all patients (randomized plus non-randomized) the proportion who achieved this goal at Week 12 was 27.4\% (596/2173). For the randomized groups, the overall proportion of patients who achieved the BP goal of $<130 / 85 \mathrm{mmHg}$ at Week 12 was $10.4 \%$ (65/627). In the individual randomized groups, the proportion of patients who achieved the combined BP goal of $<130 / 85 \mathrm{mmHg}$ was higher in the group that received combination therapy (Figure 2a). In patients who received olmesartan monotherapy only, 29.9\% (553/1848) achieved the $<130 / 85 \mathrm{mmHg}$ goal.

Looking at patients with diabetes among the nonrandomized patients, $16.4 \%$ achieved the guidelinerecommended goal of $130 / 80 \mathrm{mmHg}$ at Week 12. For randomized patients, the proportion who achieved the (a)

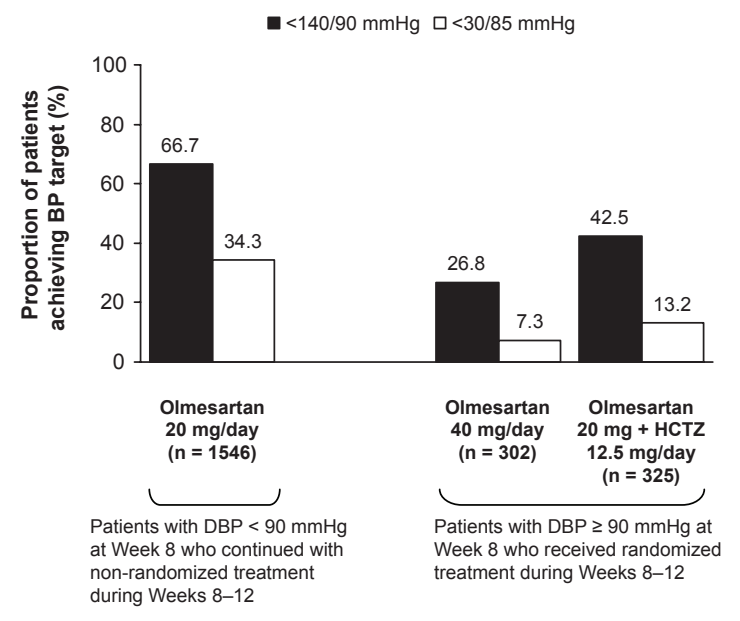

(b)

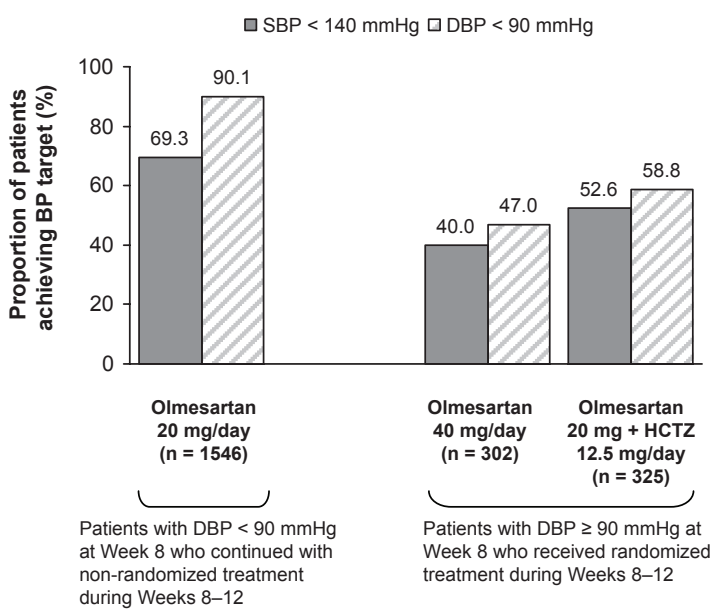

Figure 2 Blood pressure (BP) goal achievement rates at Week 12 for (a) combined systolic and diastolic BP (SBP and DBP) goals and for (b) individual SBP and DBP goals.

$130 / 80 \mathrm{mmHg}$ goal was $6.7 \%$ and $9.7 \%$ in the olmesartan $40 \mathrm{mg} /$ day and olmesartan $20 \mathrm{mg} /$ day plus HCTZ $12.5 \mathrm{mg}$ /day groups, respectively.

\section{Safety evaluation}

AEs reported in the OLMEBEST study have been reported previously, ${ }^{14}$ and are described only briefly here. Generally, similar proportions of patients experienced AEs of mild, moderate and severe intensity during open-label treatment and in the two randomized treatment groups. During randomized treatment, olmesartan $40 \mathrm{mg}$ /day was associated with a somewhat lower frequency of AEs than olmesartan $20 \mathrm{mg}$ plus HCTZ $12.5 \mathrm{mg} /$ day $(21.5 \%$ vs $28.3 \%$ of patients, respectively). The majority (72.4\%) of the AEs were classified as being of mild intensity and only $6.4 \%$ of events were considered probably or definitely related to study drug. Dizziness (1.4\%) and headache $(2.5 \%)$ were 
the most commonly reported AEs in each group during randomized treatment. AEs that led to withdrawal from the study were reported in 7 patients in the olmesartan $40 \mathrm{mg}$ group and 9 in the olmesartan plus HCTZ group. No serious AEs were considered to be related to study medication.

At week 12, patients treated with olmesartan $40 \mathrm{mg} /$ day and olmesartan $20 \mathrm{mg}$ plus HCTZ $12.5 \mathrm{mg}$ /day showed comparable mean serum concentrations of glucose ( 5.55 and $5.63 \mathrm{mmol} / \mathrm{L}$, respectively), sodium (140.9 and $140.3 \mathrm{mmol} / \mathrm{L}$, respectively), potassium (4.40 and $4.26 \mathrm{mmol} / \mathrm{L}$, respectively), and creatinine $(82.8$ and $81.6 \mu \mathrm{mol} / \mathrm{L}$, respectively). The incidence of laboratory measurements reported as being of potential clinical relevance during randomized treatment was low. Increases in serum levels were reported for alanine aminotransferase (olmesartan $20 \mathrm{mg}$ plus HCTZ $12.5 \mathrm{mg}$ /day group, $\mathrm{n}=2$ ), aspartate aminotransferase (olmesartan $20 \mathrm{mg}$ plus HCTZ $12.5 \mathrm{mg} /$ day, $\mathrm{n}=2$ ), $\gamma$-glutamyltransferase (olmesartan $40 \mathrm{mg} /$ day, $\mathrm{n}=2$; and olmesartan $20 \mathrm{mg}$ plus HCTZ $12.5 \mathrm{mg} /$ day, $\mathrm{n}=4$ ), glucose (olmesartan $40 \mathrm{mg} /$ day, $\mathrm{n}=1$; and olmesartan $20 \mathrm{mg}$ plus HCTZ $12.5 \mathrm{mg} /$ day, $\mathrm{n}=3$ ), and creatinine (olmesartan $40 \mathrm{mg} /$ day, $\mathrm{n}=1$ ).

\section{Discussion}

OLMEBEST was a large study involving approximately 2300 patients that confirmed the efficacy of the standard maintenance dose of olmesartan $20 \mathrm{mg}$ /day and suggested that for patients who did not show a sufficient response, antihypertensive efficacy could be increased by either dosetitration or the addition of a low dose of HCTZ. In each of the two randomized groups, additional reductions in SBP and DBP were seen relative to the end of the open-label monotherapy phase. ${ }^{14}$

Monotherapy dose-titration or combination therapy is recommended in patients who do not respond adequately to initial monotherapy. ${ }^{4}$ The results of this analysis show that treatment of hypertensive patients with olmesartan $20 \mathrm{mg} /$ day plus HCTZ $12.5 \mathrm{mg} /$ day or uptitration to olmesartan $40 \mathrm{mg} /$ day for patients with a sub-optimal response, enabled more than half of all patients to achieve an SBP/DBP target of $<140 / 90 \mathrm{mmHg}$ in OLMEBEST. Looking at the whole study population, the proportion of patients who achieved the 140/90 $\mathrm{mmHg}$ goal approached $60 \%$ at Week 12 .

Approximately $70 \%$ of patients achieved DBP normalization $(<90 \mathrm{mmHg})$ after 8 weeks of open-label treatment with olmesartan $20 \mathrm{mg} /$ day. However, approximately $30 \%$ of patients did not achieve DBP normalization and went on to receive randomized treatment. By the end of the study, more than half of these randomized patients who had already shown an inadequate DBP response to olmesartan $20 \mathrm{mg} /$ day had achieved DBP normalisation, and more than a third had achieved the $<140 / 90 \mathrm{mmHg}$ goal.

The rate of DBP normalization achieved with olmesartan $20 \mathrm{mg}$ /day during the 8-week open-label phase was higher than anticipated during the design of the study. Thus, fewer patients than planned were randomized to treatment, which meant that the study did not have sufficient power to detect non-inferiority between the two treatment groups. As such, it was not possible to determine whether there was a statistically significant difference between the two randomized groups. Despite this limitation, the olmesartan plus HCTZ arm appeared to be associated with a higher level of goal achievement compared with uptitration to olmesartan $40 \mathrm{mg} /$ day. This finding is probably explained by the complementary modes of action of ARBs and HCTS that result in increased antihypertensive efficacy. ${ }^{15}$ Indeed, the combination of olmesartan and HCTZ has previously been associated with larger BP reductions compared with uptitration of component monotherapy. ${ }^{16}$

The partially-randomized design of the OLMEBEST study makes it difficult to compare the results with those of other studies. Adding HCTZ to an ARB increases antihypertensive efficacy, as outlined above, and the combination of olmesartan with HCTZ has been available for several years. ${ }^{17}$ Rump et al looked at the effects of treatment with olmesartan $20 \mathrm{mg} /$ day plus HCTZ $12.5 \mathrm{mg}$ /day and found that after 12 weeks the proportion of patients with $\mathrm{BP}<140 / 90 \mathrm{mmHg}$ was $43 \%,{ }^{18}$ which is in line with the results of the present analysis for the randomized group that received combination therapy. Combining HCTZ with other ARBs has also been shown to result in comparable levels of goal rate achievement. The combination of HCTZ $12.5 \mathrm{mg} /$ day with either candesartan $8 \mathrm{mg}$ /day or valsartan $80 \mathrm{mg}$ /day resulted in approximately $49 \%$ of hypertensive patients achieving $<140 / 90 \mathrm{mmHg}$ with each combination, ${ }^{19}$ although a more recent analysis by Weir et al indicates a level closer to $40 \%$ for valsartan plus HCTZ. ${ }^{20}$ For dose-titration, Neutel et al conducted a forced-titration study in which patients were treated with the aim of achieving a BP target of $<130 / 85 \mathrm{mmHg}^{21}$ During the initial monotherapy phase of the present study, patients received olmesartan $20 \mathrm{mg}$ /day for 4 weeks, followed by uptitration to olmesartan $40 \mathrm{mg}$ /day for the next 
4 weeks for patients who did not achieve target BP. At the end of the 8-week monotherapy phase, the proportion of patients who achieved the BP target of $<140 / 90 \mathrm{mmHg}$ was $58.7 \%$, a value similar to that observed for all patients who received olmesartan as monotherapy (either $20 \mathrm{mg}$ /day or $40 \mathrm{mg}$ /day) in OLMEBEST.

In many countries, overall levels of BP control in the general population are suboptimal ${ }^{22-24}$ and need to be improved in order to lower the rate of $\mathrm{CV}$ events such as stroke and myocardial infarction. Increasing the dose of monotherapy or using a two-drug combination is recommended in order to achieve BP control. ${ }^{4}$ The results of the present analysis support this approach, and suggest that each of these approaches can be used to increase the number of patients achieving the recommended $<140 / 90 \mathrm{mmHg}$ hypertension threshold. Moreover, this analysis also looked at the more rigorous BP goal of $<130 / 85 \mathrm{mmHg}$ and found that by Week 12, 27.4\% of all patients had achieved this goal and had thus achieved a level of BP control below the ESH-ESC threshold for high normal ${ }^{4}$ and so could be regarded as being within the normal range.

In conclusion, treatment with olmesartan $20 \mathrm{mg} /$ day enabled a substantial proportion of patients to achieve the guideline-recommended goal of $<140 / 90 \mathrm{mmHg}$, and approximately two-thirds of patients receiving olmesartan $20 \mathrm{mg} /$ day at the end of the study achieved this goal. For patients who had been unable to normalize their DBP with olmesartan $20 \mathrm{mg}$ /day, addition of HCTZ $12.5 \mathrm{mg} /$ day to the regimen, or dose uptitration to olmesartan $40 \mathrm{mg}$ /day enabled even more patients to control their BP so that overall, nearly $60 \%$ of patients had a BP $<140 / 90 \mathrm{mmHg}$ by study end. Such findings indicate that both uptitration and combination with HCTZ are effective options to achieve increased BP reduction and goal attainment, but clinical recommendations as to the most appropriate regimen must be decided by physicians based on individual patients' needs.

\section{Acknowledgments and disclosures}

This study was sponsored by Daiichi Sankyo Europe GmbH, Munich, Germany. The authors thank Dr Phil Jones from Wolters Kluwer Health (Chester, UK) who provided medical writing assistance funded by Daiichi Sankyo Europe.

Professor Barrios has worked as a consultant for Daiichi Sankyo Europe.

\section{References}

1. World Health Organization. Reducing risks, promoting healthy life 2002 [cited 2008 July 30]. http://www.who.int/whr/2002/en/whr02_ en.pdf. Accessed August 6, 2009.

2. Kannel WB. Blood pressure as a cardiovascular risk factor: prevention and treatment. JAMA. 1996;275:1571-1576.

3. Chobanian AV, Bakris GL, Black HR, et al. The Seventh Report of the Joint National Committee on Prevention, Detection, Evaluation, and Treatment of High Blood Pressure: the JNC 7 report. JAMA. 2003; 289:2560-2572.

4. Mancia G, De Backer G, Dominiczak A, et al. 2007 Guidelines for the Management of Arterial Hypertension: The Task Force for the Management of Arterial Hypertension of the European Society of Hypertension (ESH) and of the European Society of Cardiology (ESC). J Hypertens. 2007;25:1105-1187.

5. Birkenhager WH, de Leeuw PW. Non-peptide angiotensin type 1 receptor antagonists in the treatment of hypertension. $J$ Hypertens. 1999;17:873-881.

6. Ball KJ, Williams PA, Stumpe KO. Relative efficacy of an angiotensin II antagonist compared with other antihypertensive agents. Olmesartan medoxomil versus antihypertensives. J Hypertens Suppl. 2001; 19:S49-S56.

7. Brunner HR, Arakawa K. Antihypertensive efficacy of olmesartan medoxomil and candesartan cilexetil in achieving 24-hour blood pressure reductions and ambulatory blood pressure goals. Clin Drug Investig. 2006;26:185-193.

8. Brunner HR, Laeis P. Clinical efficacy of olmesartan medoxomil. J Hypertens Suppl. 2003;21:S43-S46.

9. Giles TD, Oparil S, Silfani TN, et al. Comparison of increasing doses of olmesartan medoxomil, losartan potassium, and valsartan in patients with essential hypertension. J Clin Hypertens (Greenwich) 2007;9:187-195.

10. Oparil S, Williams D, Chrysant SG, et al. Comparative efficacy of olmesartan, losartan, valsartan, and irbesartan in the control of essential hypertension. J Clin Hypertens (Greenwich). 2001;3:283-291, 318.

11. Neutel JM. Clinical studies of CS-866, the newest angiotensin II receptor antagonist. Am J Cardiol. 2001;87:37C-43C.

12. Püchler K, Laies P, Stumpe KO. Blood pressure response, but not adverse event incidence, correlates with dose of angiotensin II antagonist. J Hypertens Suppl. 2001;19:s41-s48.

13. Sellin L, Stegbauer J, Laeis P, et al. Adding hydrochlorothiazide to olmesartan dose dependently improves 24 -h blood pressure and response rates in mild-to-moderate hypertension. J Hypertens. 2005;23:2083-2092.

14. Barrios V, Boccanelli A, Ewald S, et al. Efficacy and tolerability of olmesartan medoxomil in patients with mild to moderate essential hypertension: the OLMEBEST study. Clin Drug Investig. 2007;27: $545-558$.

15. Kjeldsen S, Os I, Høieggen A. Fixed-dose combinations in the management of hypertension: defining the place of angiotensin receptor antagonists and hydrochlorothiazide. Am J Cardiovasc Drugs. 2005;5:17-22.

16. Chrysant S, Weber M, Wang A. Evaluation of antihypertensive therapy with the combination of olmesartan medoxomil and hydrochlorothiazide. Am J Hypertens. 2004;17:252-259.

17. Barrios V, Escobar C. Olmesartan medoxomil plus hydrochlorothiazide for treating hypertension. Expert Opin Pharmacother. 2008;9:129-136.

18. Rump L, Ambrosioni E, Burnier M, et al. Initial combination therapy with olmesartan/hydrochlorothiazide in moderate-to-severe hypertension. J Hum Hypertens. 2006;20:299-301.

19. Wagstaff AJ. Valsartan/hydrochlorothiazide: a review of its use in the management of hypertension. Drugs. 2006;66:1881-1901.

20. Weir MR, Crikelair N, Levy D, et al. Evaluation of the dose response with valsartan and valsartan/hydrochlorothiazide in patients with essential hypertension. J Clin Hypertens (Greenwich) 2007;9:103-112. 
21. Neutel JM, Smith DH, Weber MA, et al. Use of an olmesartan medoxomil-based treatment algorithm for hypertension control. J Clin Hypertens (Greenwich) 2004;6:168-174.

22. Barrios V, Banegas JR, Ruilope LM, et al. Evolution of blood pressure control in Spain. J Hypertens. 2007;25:1975-1977.

23. Barrios V, Escobar C, Calderon A, et al. Blood pressure and lipid goal attainment in the hypertensive population in the primary care setting in Spain. J Clin Hypertens (Greenwich). 2007;9:324-329.
24. Wolf-Maier K, Cooper RS, Kramer H, et al. Hypertension treatment and control in five European countries, Canada, and the United States. Hypertension. 2004;43:10-17.

\section{Publish your work in this journal}

Vascular Health and Risk Management is an international, peerreviewed journal of therapeutics and risk management, focusing on concise rapid reporting of clinical studies on the processes involved in the maintenance of vascular health; the monitoring, prevention and treatment of vascular disease and its sequelae; and the involvement of metabolic disorders, particularly diabetes. This journal is indexed on PubMed Central and MedLine. The manuscript management system is completely online and includes a very quick and fair peer-review system, which is all easy to use. Visit http://www.dovepress.com/ testimonials.php to read real quotes from published authors.

Submit your manuscript here: http://www.dovepress.com/vascular-health-and-risk-management-journal 